\title{
Designs on Pandemic and Post-Pandemic Meetings: Learning with the EPSC 2021 Team
}

\author{
By Amy Riches \\ School of Geosciences, University of Edinburgh, UK, and SETI Institute, USA. \\ @PlanetaryAmy
}

DRAFT. 943 words omitting the ref. list. Submitted, Europlanet Society Magazine. Planetary Geochemist Diving into the Media Team

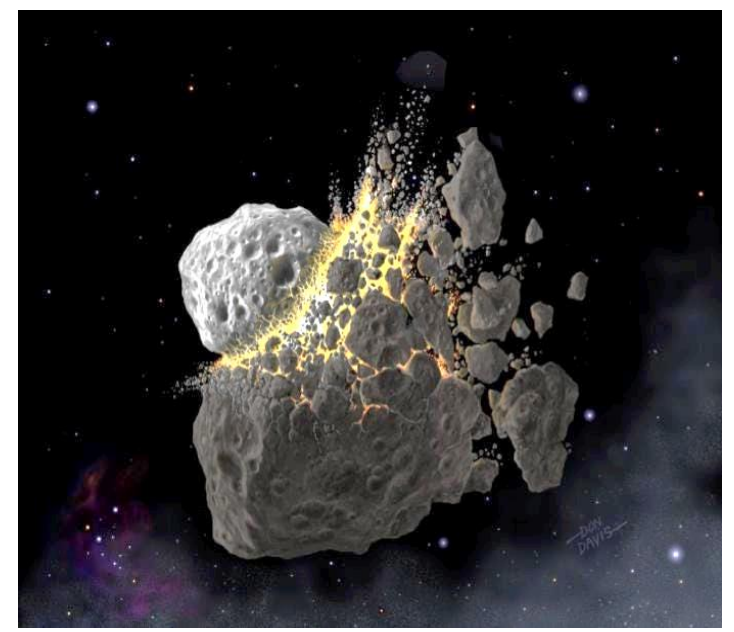

Image Credit: Artists impression of an impact among asteroids giving rise to fragments that become meteoroids some to later fall to Earth as meteorites. Don Davis, Southwest Research Institute.

Crucial to science is sharing with others; there are more ways to do so than any one of us can imagine alone and as with all we do it is important to work together.

The 'hat' I usually wear is that of petrologist and geochemist deciphering the history of our Solar System as embedded in slices of rocks studied via microscopes and various mass spectrometry approaches that tease out rocky stories over a span of $\sim 4.6$ billion years. Included among my chemical tools of choice are the 'highly siderophile element' group and related isotopic tracers (cf. a Special Issue of Geochimica et Cosmochimica Acta). In conducting this form of research on meteorites planned work and completed research student projects engage the Europlanet Society's Distributed Planetary

Laboratory Facility as well as the UK's Cosmochemical Analysis Network.

Yet, what more can we do? Write! It was a great privilege to be part of the Media Team for the Europlanet Science Congress (EPSC) Virtual 2021; a lot of fun with a group of talented people as we reported on new results and eagerly immersed ourselves in as much of the meeting as possible. An event where we have catch-up access to recordings over a full year - what a treat!

So, what exactly did I contribute? My role involved liaising with scientists and writing press releases concerning a meteorite-dropping fireball over Slovenia and 'exotic' fragments of the Moon recovered by China's Chang'e-5 sample return mission. Helping to propel exciting science into international news! Plus, I pitched in to support the Social Media Team with a bit of tweeting under the \#EPSC2021 tag. It was a great experience that I learnt a lot from while making new professional friends and balancing other commitments. I can certainly recommend giving this type of activity and training a try.

\section{Banding Together in a Changed World}

The COVID-pandemic has been a serious time with sad losses of life across the world. This difficult time necessitated changes to the ways in which we work and prompted deep reflection concerning how societies operate, support, include one another, and must adapt and progress with the times (e.g. Riches et al., 2021, Pourret et al., 2021, and a European Commission statement). Increasing amounts of emerging evidence among, for example, 
scientific publishers (Myers et al., 2020) show that the COVID-crisis has exacerbated longstanding inequities among scientific communities. This emphasises the urgency required in deconstructing cultural and systemic barriers faced by scientists of underrepresented groups. Hence, as Co-Chair of the European Association of Geochemistry's Diversity, Equity, and Inclusion Committee the understanding gained from interacting with the Europlanet Society's Early Career Network (EPEC) and Diversity Committee during EPSC shall feed into our own activities and assist reciprocal exchange in future.

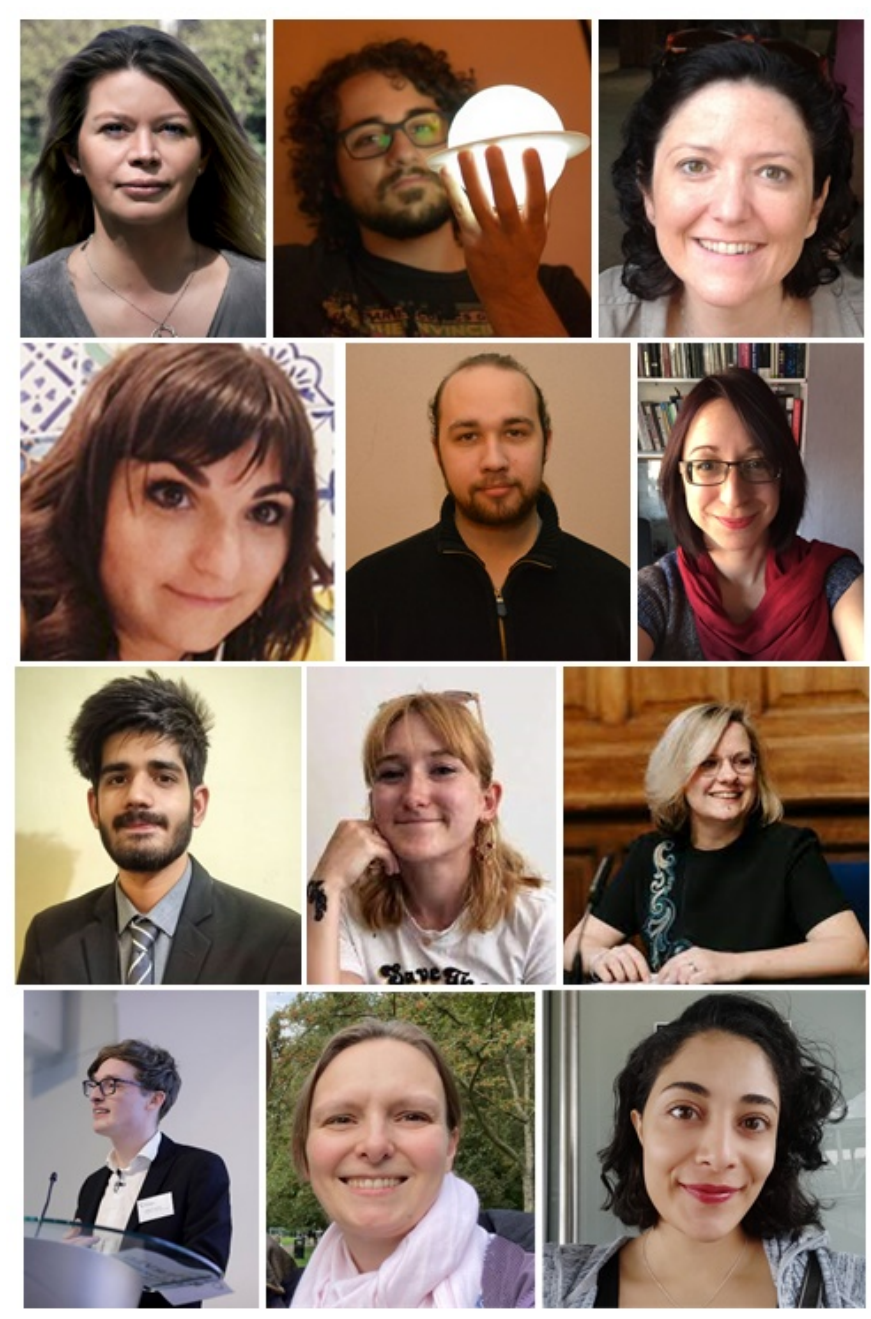

Europlanet Science Congress Virtual 2021, Communications Team.

From top left: The Media Team composed of Anita Heward, Luca Nardi, Livia Giacomini,

Adriana Postiglione, Thibault Roger, and Amy Riches. Plus the social media team comprising Siddhant Sharma, Grace Richards, Kateryna Frantseva, James McKevitt, and Vix Southgate. Everyone is appreciative of Shorouk Elkobros' (bottom right) involvement.
International conferences such as EPSC have long brought scientists together and been prominent on our calendars. Given the excitement and anticipation that communities feel as work is prepared for these events, the shift to fully virtual meetings has sparked a range of responses, necessitated flexibility among organising teams, and prompted changes not only in how and from where talks are given but in the ways that we network.

\section{Streaming and Beaming in your Homes}

In remotely attending this year's EPSC not only did I learn a great deal from all of the speakers, but so too did my cat and all be it briefly - the occasional mail delivery person. It was a thrill to instantly 'find the room' and have time to attend every keynote lecture!

Of course fully virtual meetings cannot solve persisting needs for child care provisions and other support of people's needs during conferences, nor do they offer in-person networking that many of us have long been familiar with. But at EPSC the chat function during live presentations, the virtual community events, and the slack channels I found to be effective forums for exchange and potentially a little less intimidating for some people. In particular, members of scientific communities who have caring responsibilities or mental health / neurological differences that pose barriers to attending in-person meetings have reported on the benefits to them in accessing and enjoying virtual conferences (e.g. Pourret, 2020; Lawrence, 2021); factors aiding the tackling of ableism (cf. Brown and Leigh, 2020). 


\section{Opportunities Benefitting all of our Futures}

As we emerge into a changing world mindful of our duty of care for the safety and welfare of others, scientific conferences will never be the same. It has been valuable to learn through the various virtual practices and experiences of the recent EPSC, the $\underline{52^{\text {nd }}}$ Lunar and Planetary Science Conference and the Goldschmidt 2021 Virtual Conference. If travel and recovery from jet-lag had been required I would certainly not have had time, or been choosing responsibly, in attending / presenting work at all three of these 2021 international events, supplemented by presentations at smaller gatherings too. Especially during the run-up to the hybrid format and inaugural Forming and Exploring Habitable Worlds meeting taking place in Edinburgh on the $7^{\text {th }}$ to $13^{\text {th }}$ of November 2022, with support from its Scientific Steering Committee and sponsors. This event in Edinburgh shall facilitate a range of useful discussions while providing for opportunities beneficial across career stages, including some planned publishing projects.
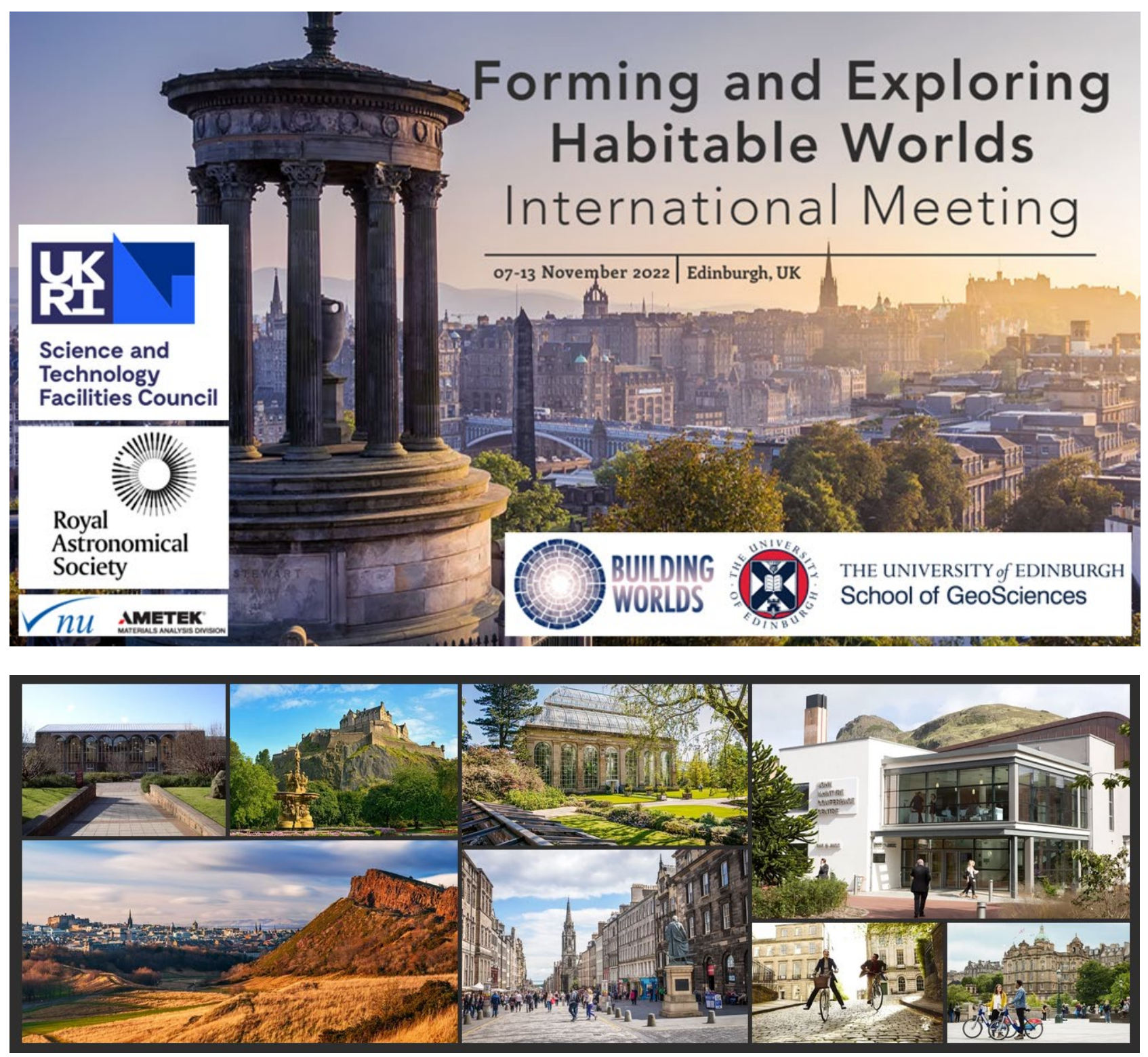

With conference formats reformed, it remains as important as ever for cooperative communities to unite in exchanging new findings, testable ideas, and sharing best practices that will accelerate scientific progress. As the opportunities of the recent EPSC taught me a great deal I am as eager as ever to engage with the science of the Europlanet community and others again soon, and as part of the approaching meeting in Edinburgh! 


\section{References}

Brown, N. and Leigh, J., 2020. Ableism in Academia: Theorising experiences of disabilities and chronic illnesses in higher education. UCL Press.

https://discovery.ucl.ac.uk/id/eprint/10110703/1/Ableism-in-Academia.pdf

Lawrence, A., 2021. How Zoom helped the neurotypical world hear my autistic voice. Nature. https://www.nature.com/articles/d41586-021-02325-9

Myers, K.R., Tham, W.Y., Yin, Y., Cohodes, N., Thursby, J.G., Thursby, M.C., Schiffer, P., Walsh, J.T., Lakhani, K.R. and Wang, D., 2020. Unequal effects of the COVID-19 pandemic on scientists. Nature human behaviour, 4(9), pp.880-883.

https://www.nature.com/articles/s41562-020-0921y?fbclid=IwAR2uJXs955CE0Zx6vTVGGeyLddHtoRfTCZDrWqEYz SVgPhfnC8Y4ywyPoE

Pourret, O., 2020. Why scientists with children who have disabilities need a different career trajectory. Nature. https://www.nature.com/articles/d41586-020-02043-8

Pourret, O., Anand, P., Arndt, S., Bots, P., Dosseto, A., Li, Z., Carbonne, J.M., Middleton, J., Ngwenya, B. and Riches, A.J., 2021. Diversity, Equity, and Inclusion: tackling under-representation and recognition of talents in Geochemistry and Cosmochemistry. Geochimica et Cosmochimica Acta.

https://doi.org/10.1016/j.gca.2021.05.054

Riches, A., Pourret, O. and Little, S., 2021. Uniting to Advance Diversity, Equity, and Inclusion in a Pandemic and Post-Pandemic World. EAG Blog.

Blog: https://blog.eag.eu.com/news/uniting-to-advance-diversity-equity-and-inclusion-in-a-pandemic-andpost-pandemic-world/

Pre-print: https://osf.io/d6z72 